\title{
RECQ helicases are deregulated in hematological malignancies in association with a prognostic value
}

\author{
Elena Viziteu ${ }^{2}$, Alboukadel Kassambara ${ }^{1,2}$, Philippe Pasero ${ }^{2}$, Bernard Klein ${ }^{1,2,3}$ and Jerome Moreaux ${ }^{1,2,3^{*}}$ (D)
}

\begin{abstract}
Background: RECQ helicase family members act as guardians of the genome to assure proper DNA metabolism in response to genotoxic stress. Hematological malignancies are characterized by genomic instability that is possibly related to underlying defects in DNA repair of genomic stability maintenance.

Methods: We have investigated the expression of RECQ helicases in different hematological malignancies and in their normal counterparts using publicly available gene expression data. Furthermore, we explored whether RECQ helicases expression could be associated with tumor progression and prognosis.

Results: Expression of at least one RECQ helicase family member was found significantly deregulated in all hematological malignancies investigated when compared to their normal counterparts. In addition, RECQ helicase expression was associated with a prognostic value in acute myeloid leukemia, chronic lymphocytic leukemia, lymphoma and multiple myeloma.

Conclusion: RECQ helicase expression is deregulated in hematological malignancies compared to their normal counterparts in association with a prognostic value. Deregulation of RECQ helicases appears to play a role in tumorigenesis and represent potent therapeutic targets for synthetic lethal approaches in hematological malignancies.
\end{abstract}

Keywords: RECQ helicases, Gene expression, Hematological malignancies, Prognostic markers, Therapeutic targets

\section{Background}

The RECQ family of DNA helicases is a family of conserved enzymes that display highly-specialized and vital roles in the maintenance of genome stability [1].

In humans, RECQ helicase family has five members with similar catalytic core: RECQ1, BLM, WRN, RECQ4 and RECQ5 [1]. Mutations in three of the five human RECQ helicases, BLM, WRN and RECQ4, lead to genetic disorders as Bloom, Rothmund-Thompson and Werner's syndromes that are associated with cancer predisposition, premature ageing and developmental abnormalities [1,2].

The Bloom's syndrome helicase, BLM has DNA annealing and unwinding activities. Through its interaction with TOPOIII $\alpha$, BLM unwinds the short stretches of naked

\footnotetext{
* Correspondence: jerome.moreaux@igh.cnrs.fr

${ }^{1}$ Laboratory for Monitoring Innovative Therapies, Department of Biological Hematology, Hôpital Saint-Eloi - CHRU de Montpellier, 80, av. Augustin Fliche, 34295 Montpellier, Cedex 5, France

${ }^{2}$ Institute of Human Genetics, CNRS-UPR1142, Montpellier F-34396, France Full list of author information is available at the end of the article
}

duplex DNA and processes homologous recombination (HR) intermediates containing a double holiday junction $[1,2]$. This helicase appears to prefer specific structures including D-loops and Holliday junctions and promotes Holliday junction branch migration [3]. It may suppress hyper-sister chromatid exchange (SCE) by disruption of D-loop recombination intermediates and also might be involved in the suppression of crossing over during homology-mediated recombination [4]. BLM-mediated crossover suppression may involve synthesis-dependent strand annealing (SDSA) [3]. This helicase facilitates telomere replication by resolving G4 structures [5]. Defects in BLM are also associated with the cancer phenotype [4].

Unlike the other members of the RECQ helicase family, the Werner's syndrome helicase, WRN contains both the classical helicase activity and 3'-to 5' exonuclease activity that target multiple DNA or RNA-DNA hybrid structures $[1,2]$. As BLM, WRN appears to have robust in vitro G4 
unwinding activity [6] and plays a specialized role in telomere replication by disruption of G-quadruplex stretches [7]. Another specific substrate of WRN is D-loop. WRN repress the inappropriate telomeric recombination intermediates through its ability to resolve the D-loops [8]. This helicase was found to be involved in the repair of double strand DNA breaks and studies on Werner's syndrome fibroblasts have shown defects in recombination intermediate resolution which suggests that WRN is involved in HR [9]. WRN can bind to NBS1 [10], a member of the MRN complex, and to the Ku70/Ku80 heterodimer [11], a core non-homologous end joining DNA repair (NHEJ) complex.

RECQ1 is the shortest of the human RECQ family helicases. RECQ1 displays specific functions in branch migration and restart of reversed DNA replication forks upon DNA topoisomerase I inhibition that is not shared by other human RECQ helicases [12, 13]. Studies have also shown that RECQ1 plays a role in DNA strand breaks repair, mismatch repair and resistance to replication stress [1, 2, 13, 14]. RECQ1 can also contribute to tumor development and progression by regulating the expression of key genes that promote cancer cell migration, invasion and metastasis [15].

The gene encoding for RECQ5 helicase was found to be localized on human chromosome 17q23-25, a region associated with both breast and ovarian cancer [16]. RECQ5 was found to cause a significant increase in the frequency of spontaneous SCE [1, 2]. As BLM, RECQ5 was shown to play an essential role in suppression of crossovers [17]. RECQ5 was identified as a potential proto-oncogene in mouse leukemia [18]. RECQ5 is the only member of RECQ family associated with RNA polymerase II, maintaining genomic stability during transcription [19].

RECQ helicase are at the crossroad between replication, recombination, DNA repair and transcription and could represent potent therapeutic targets for cancer therapy [20]. Hematological malignancies are characterized by genomic instability that is possibly related to underlying defects in DNA repair of genomic stability maintenance. Since these helicases play important roles in the maintenance of chromosomal stability [21], we focused on RECQ helicases expression in hematological cancers compared to their normal counterparts and the association with prognostic impact.

\section{Results and discussion}

RECQ helicase gene expression levels were analyzed in different types of hematological malignancies and in their normal counterparts using Oncomine Cancer Microarray database [22] as indicated in Table 1. Abnormal expression of at least one RECQ helicase was identified in all analyzed hematological malignancies (Table 1). RECQ1 was found to be significantly overexpressed in mantle cell lymphoma $(P=0.0025)$ [23], in unspecified peripheral T-cell lymphoma $(P=0.0038)[24]$, anaplastic large lymphoma $(P=0.0024)[24]$ and angioimmunoblastic large cell lymphoma $(\mathrm{P}=0.001)$ [24] (Fig. 1a).

WRN is significantly overexpressed in primary effusion lymphoma compared to normal B cells $(p=0.003)$ [23] (Fig. 1a).

RECQ4 expression was increased in Burkitt Lymphoma $(P=0.001)[23,25]$, in diffuse large B cell lymphoma $(P=0.004)$ [23] and also in primary effusion lymphoma $(P=0.005)$ [23] compared to normal counterpart (Fig. 1a).

RECQ5 is significantly overexpressed in acute myeloid leukemia $(P=0,001)$ [26] (Fig. 1a).

Comparing RECQ helicases expression between normal plasma cells (BMPC), premalignant cells from MGUS patients and multiple myeloma cells (MMC) [27], BLM and WRN were found to be significantly downregulated in MMC compared to normal $\operatorname{BMPC}(P=0.002$ and $P=$

Table 1 RECQ family member expression in hematological malignancies compared to that of their normal tissue counterparts using publicly available gene expression data, including the Oncomine Cancer Microarray and Genomicscape databases

\begin{tabular}{|c|c|c|c|c|c|c|c|}
\hline & \multirow[t]{2}{*}{ Hematological Malignancies } & \multirow[t]{2}{*}{ Datasets } & \multicolumn{5}{|c|}{ Gene overexpression compared to normal tissue counterpart } \\
\hline & & & RECQ1 & $B L M$ & WRN & RECQ4 & RECQ5 \\
\hline Myeloid Neoplasms & Acute Myeloid Leukemia & 12 & No & No & No & No & YES \\
\hline \multirow[t]{6}{*}{ B-cell neoplasms } & Primary Effusion Lymphoma & 8 & No & No & YES & YES & No \\
\hline & Chronic Lymphocyte Leukemia & 11 & No & No & YES & No & No \\
\hline & Diffuse Large B-cell Lymphoma & 8 & No & No & No & YES & No \\
\hline & Burkitt's Lymphoma & 8 & No & No & No & YES & No \\
\hline & Mantle Cell Lymphoma & 11 & YES & No & No & No & No \\
\hline & Multiple Myeloma & 1 & YES & YES & YES & YES & No \\
\hline \multirow[t]{3}{*}{ T-cell neoplasms } & Unspecified Peripheral T-cell Lymphoma & 11 & YES & No & No & No & No \\
\hline & Anaplastic Large Cell Lymphoma & 11 & YES & No & No & No & No \\
\hline & Angioimmunoblastic T-Cell Lymphoma & 11 & YES & No & No & No & No \\
\hline
\end{tabular}




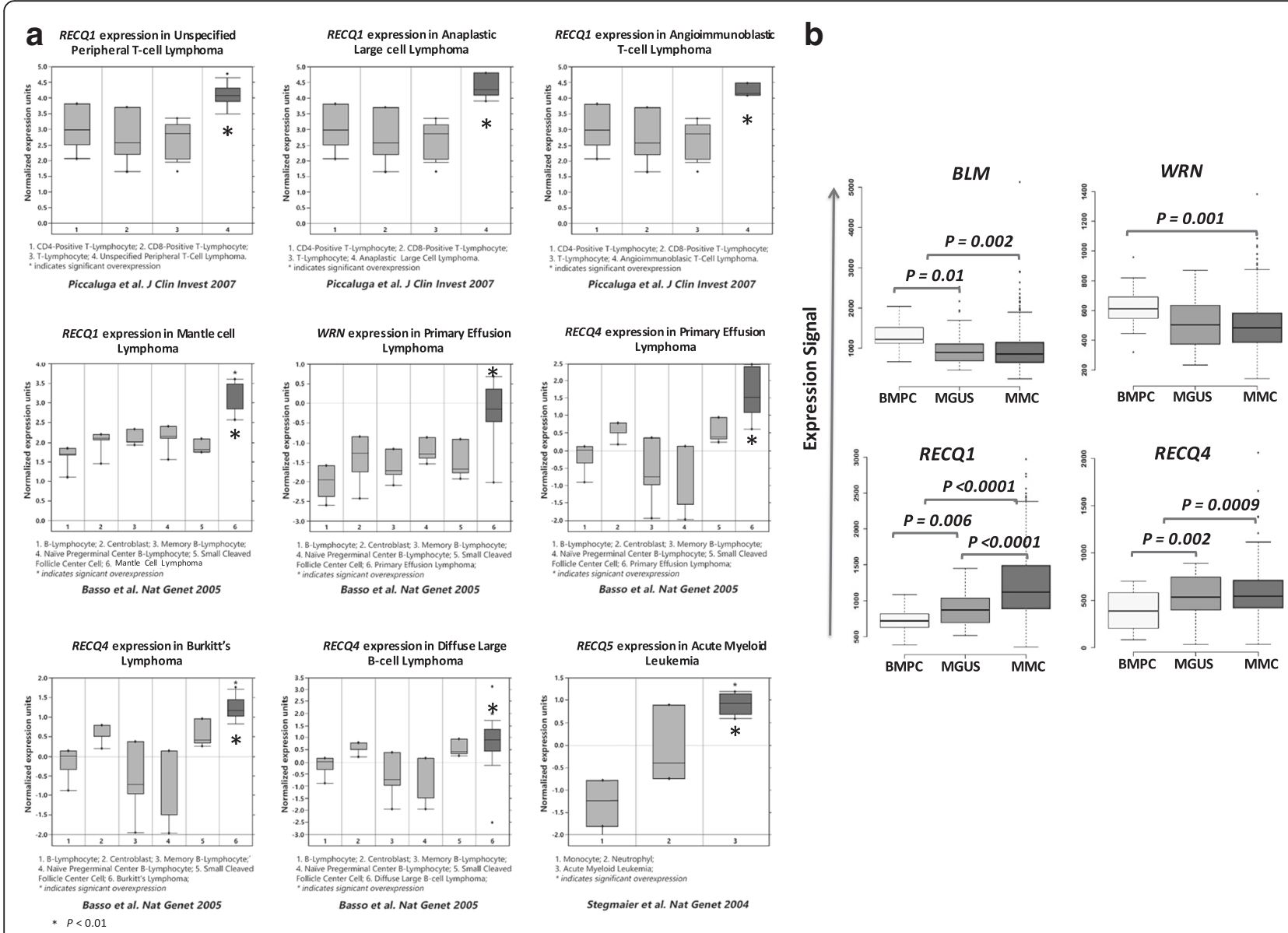

Fig. 1 Increased RECQ helicase gene expression in hematological malignancies compared to normal counterparts using Oncomine database (a) and Genomicscape database (b). Data sets in a given panel were from the same study. GEP data are log transformed (Oncomine) or not (Genomicscape) and normalized as previously described [64]

0.001 respectively) (Fig. 1b). A decreased expression of $B L M$ was also observed in MGUS compared to BMPC $(P=0.01)$. RECQ1 and RECQ4 are overexpressed in MGUS $(P=0.006$ and $P=0.002)$ and MMC $(P<0.0001$ and $P=0.0009$ ) compared to BMPC. Furthermore, a significant increased expression of RECQ1 in MMC compared to MGUS was identified (Fig. 1b).

Furthermore, using the human protein atlas database [28-30], the expression of RECQ1, RECQ4 and RECQ5 could be confirmed at protein level in myeloid and lymphoid cancer cell lines (Additional file 1: Figure S1).

We investigated whether RECQ helicases expression could be associated with tumor progression and prognosis in hematological malignancies (Table 2).

In AML patients with abnormal karyotype (Verhaak cohort, $N=521$ patients) [31], a high expression of $B L M$ and RECQ4 is associated with a better overall survival (OS) $(P=0.01$ and $P=0.003)$. At the opposite, high RECQ5 expression was linked with a poor prognosis in the same cohort of patient $(P=0.008)$ (Fig. 2a). In cox multivariate analysis, only RECQ5 expression kept prognostic value $(P=0.01$, hazard ratio $(\mathrm{HR})=1.43$.

In AML with normal karyotype, (Metzeler cohort, $N=$ 78) [32], gene expression of four RECQ helicases out of five were identified to predict for OS. High expression of RECQ1 $(P=0.02), B L M(P=0.01)$ and RECQ5 $(P=0.03)$ were found to be associated with poor prognosis. In contrast, high RECQ4 expression was linked with a better outcome $(P=0.03)$ (Fig. 2b). When tested together in a cox multivariate analysis, only RECQ4 expression remained significant $(P=0.009$; HR $=0.4)$.

Interestingly, RECQ5 overexpression was only identified in myeloid malignancies in association with an adverse prognosis. RECQ5 increased expression was recently reported in JAK2V617F myeloproliferative neoplasms [33]. RECQ5 depletion in JAK2V617Fmutant cells impairs replication after hydroxyurea treatment leading to a significant increased doublestranded breaks and apoptosis [33]. RECQ5 represents a potent regulator of genome stability in myeloproliferative neoplasms in association with drug resistance 
Table 2 Link between RECQ helicase gene expression and prognostic value in hematological malignancies

\begin{tabular}{|c|c|c|c|c|c|c|}
\hline \multirow{3}{*}{$\begin{array}{l}\text { RECQ } \\
\text { helicase }\end{array}$} & \multicolumn{6}{|l|}{ Prognostic value } \\
\hline & \multicolumn{2}{|l|}{$\overline{\mathrm{AML}}$} & \multirow[t]{2}{*}{ LLC } & \multirow[t]{2}{*}{$\mathrm{FL}$} & \multirow[t]{2}{*}{$\mathrm{DBLCL}$} & \multirow[t]{2}{*}{$\overline{M M}$} \\
\hline & normal karyotype & abnormal karyotype & & & & \\
\hline WRN & - & - & GOOD & GOOD & - & BAD \\
\hline$B L M$ & BAD & GOOD & - & - & - & - \\
\hline RECQ1 & BAD & - & - & BAD & - & BAD \\
\hline RECQ4 & GOOD & GOOD & - & GOOD & - & BAD \\
\hline RECQ5 & BAD & - & BAD & BAD & GOOD & - \\
\hline
\end{tabular}

GOOD : A high RECQ helicase expression is associated with a better outcome

$\mathrm{BAD}:$ A high RECQ helicase expression is associated with a poor prognosis

[33]. RECQ5 overexpression could also be involved in AML pathophysiology and chemoresistance.

Even if RECQ1 mutations have been recently shown to been associated with predisposition to breast cancer [34, 35], no link between RECQ1, BLM, WRN, and RECQ4 deregulation and lymphoid malignancies were previously reported.

In chronic lymphocytic leukemia (CLL), a poor prognosis was linked with high RECQ5 expression $(P=8 \mathrm{E}-8)$ and a better outcome was associated with high WRN expression $(P=0.0006)$ (Fig. 3a).

In a cohort of patients with follicular lymphoma (FL) (Staudt cohort, $N=180$ ) [36], high RECQ1 and RECQ5 expression represented adverse prognostic factors $(P=0.003$ and $P=0.0006$ respectively) whereas RECQ4 expression was found to be associated with a good prognosis $(P=$ 0.009) (Fig. 3b). Interestingly, RECQ1, RECQ4 and $R E C Q 5$ expresison remained independent when tested in cox multivariate analysis $(P<0.0001 ; \mathrm{HR}=2.8 ; P=$ $0.002 ; \mathrm{HR}=0.49$ and $P<0.01 ; \mathrm{HR}=1.78$ respectively).

In diffuse large $\mathrm{B}$ cell lymphoma (DLBCL), only RECQ5 expression was associated with a prognostic value. Low RECQ5 expression was a poor prognostic marker in two independent cohorts of patients $(P=0.02$ in a cohort of patients treated by combination of cyclophosphamide, doxorubicin, vincristine and prednisone (CHOP) therapy $(N=181)$ and $P=0.01$ in a cohort of patients treated by Rituximab combined with CHOP (R-CHOP) regimen $(N=233))$ (Fig. 3c) [37].

In MM, high RECQ1, WRN and RECQ4 expression are associated with an adverse prognosis in the UAMS cohort treated with total therapy 2 (Fig. 4) [27].

These data demonstrate a link between RECQ helicase expression and a prognostic value in different hematological malignancies.

Hematological malignancies are characterized by genomic instability that could be related to defects in DNA repair [21]. The RECQ family of DNA helicases is a family of conserved enzymes that display highly specialized and vital roles in the maintenance of genome stability. Mutations in three of the five human RECQ helicases,
BLM, WRN and RECQL4, are associated with genetic disorders characterized by chromosomal instability and increased susceptibility to cancer including leukemia $[38,39]$. Mutations in $B L M$ result in a dramatic lowering of $B L M$ mRNA levels and premature termination of protein translation owing to nonsense-mediated mRNA decay $[1,40]$. Patients with Bloom syndrome exhibit cancer predisposition including most types of cancers and particularly non-Hodgkin's lymphoma, leukemias and carcinomas of skin, breast and colon [1]. Interestingly, a low BLM expression is associated with a poor prognosis in AML with complex karyotypes (Fig. 2a). The cancer spectrum observed in patients with Werner's syndrome is characterized mainly by cancers of mesenchymal origin and some epithelial cancers [1, 41]. RECQ4 mutations are found in Rothmund-Thomson syndrome, RAPADILINO syndrome and Baller-Gerold syndrome $[1,41]$. Rothmund-Thomson syndrome are characterized by predisposition to mainly osteosarcoma whereas RAPADILINO syndrome are linked with lymphoma and osteosarcoma predisposition [1].

Specific recurrent chromosomal translocations have been associated with DNA repair deficiencies linked with repression of DDR (DNA damage response) genes in AML [42]. In PML-RARA, PML and BLM are delocalized from the nuclear bodies into microspeckled nuclear regions [43]. All trans retinoic acid (ATRA) treatment of APL patients leads to degradation of PML-RARA and relocalization of BLM to nuclear bodies [43] suggesting that PML-RARA are involved in genomic instability in APL through disruption of BLM and PML localization and activity. Interestingly, we reported that low BLM and RECQ4 expression are associated with a poor prognosis in AML with abnormal karyotype (Fig. 2a), suggesting that downregulation of RECQ helicases could be involved in leukemogenesis and genomic instability. At the opposite, in AML with normal karyotype, RECQ1, BLM and RECQ5 high expression are associated with a poor prognosis (Fig. 2b). As reported in solid cancer, RECQ helicase overexpression could be a marker of chemoresistance and higher 

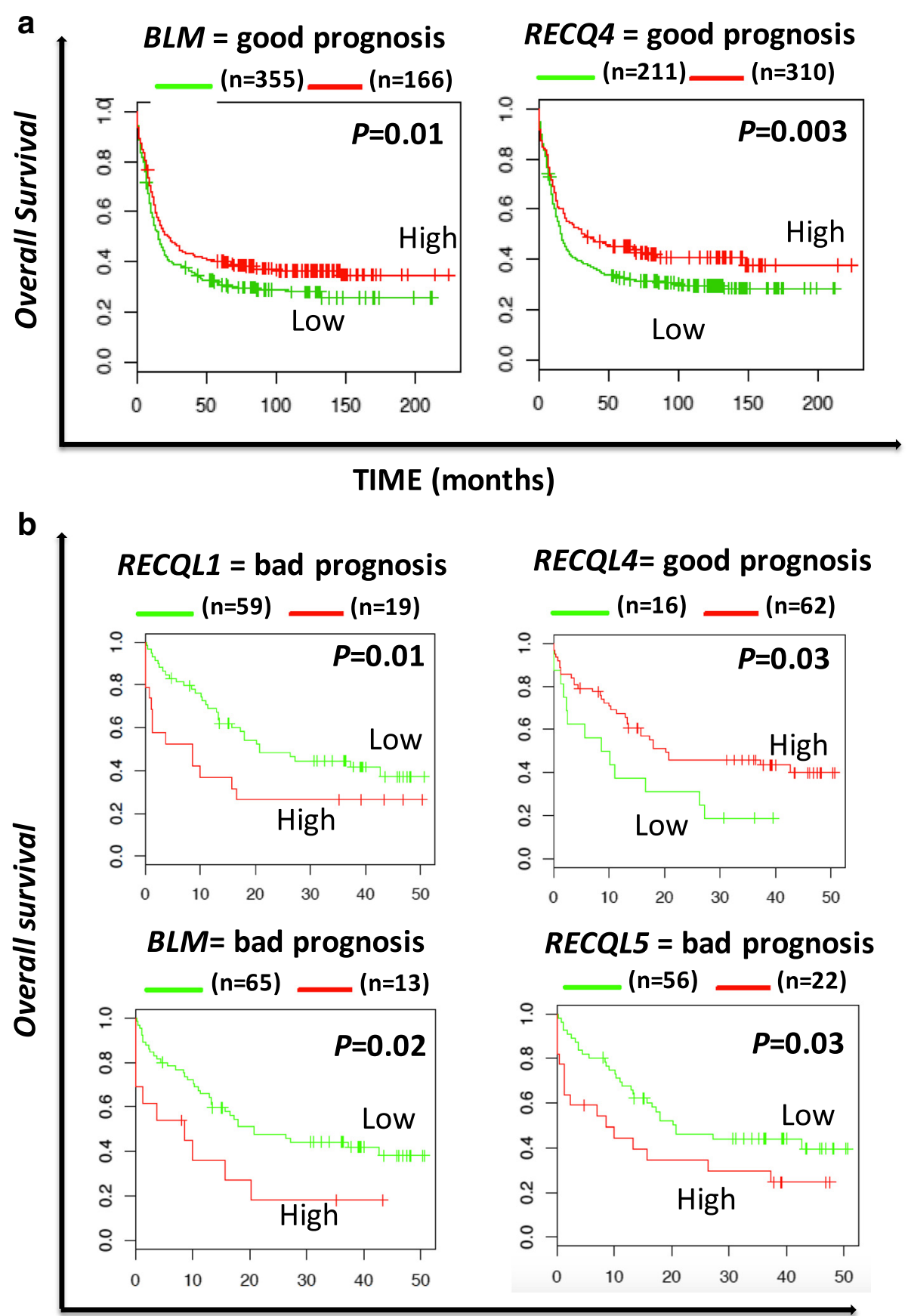

TIME (months)

Fig. 2 Overall survival related to RECQ helicase gene expression in acute myeloid leukemia with abnormal karyotype (a) and normal karyotype (b). The prognostic value of gene expression was determined using the MaxStat $\mathrm{R}$ function in $\mathrm{R}$ software. The overall survival of subgroups of patients was compared with the log-rank test and survival curves computed with the Kaplan-Meier method (R software) [66]

proliferation helping AML cells to deal with replication stress $[44,45]$. B lymphocytes are continuously produced during adult life and they undergo different genetic alterations associated with DNA breaks, including VDJ recombination, Ig class switch recombination and somatic hypermutation. These mechanisms must be tightly regulated to prevent tumorigenesis and ensure efficient immune response [46]. Collapsed DNA replication forks occurring in rapidly dividing lymphocytes leads to a restart failure and results in an interruption of the normal developmental program [47]. HR is required for lymphoid development [47]. Aberrations 

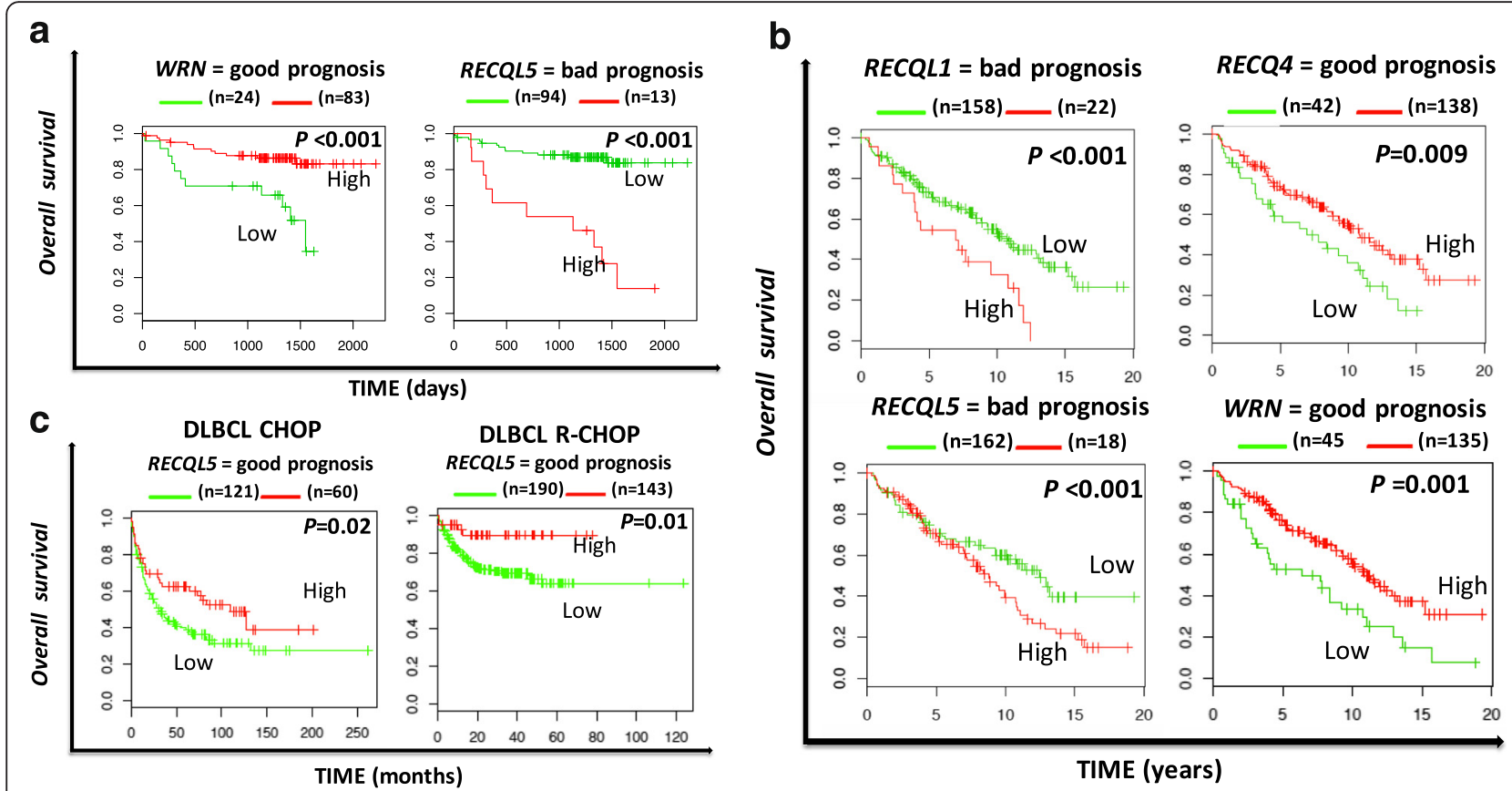

Fig. 3 Overall survival related to RECQ helicase gene expression in chronic lymphocytic leukemia (a), follicular lymphoma (b) and diffuse large B cell lymphoma (c)

affecting HR actors are correlated with genomic instability in B cell cancers [48]. By their involvement in HR and also by their ability to resolve and to continue the normal fork replication after DNA damage or replication fork arrest, WRN [49], BLM [4], RECQ1 [12] and RECQ5 [50] helicases might be crucial in lymphoid development and aberration in their expression or function can lead to cancer genesis. Interestingly, low expression of WRN in CLL and FL, low RECQ4 expression in FL and low RECQ5 in DLBCL are associated with a poor prognosis (Fig. 3). Furthermore, high RECQ5 expression in CLL and FL and high RECQ1 expression in FL are associated with a poor prognosis and could be involved in chemoresistance. In lymphoma, deregulation of DDR is associated with tumorigenesis [51, 52], poor prognosis [53, 54] and could represent a potent therapeutic target $[53,55,56]$.

In MM, patients with extensive chromosomal instability and replicative stress are associated with an adverse outcome [27, 57-59]. Accordingly, high RECQ1, WRN and RECQ4 expression is associated with a significant poor survival in MM patients (Fig. 4). Although WRN was found to be significantly downregulated in MMC compared to normal BMPC (Fig. 1b), patients with high expression display a poor prognosis. WRN is located on chromosome $8 \mathrm{p}$ deleted in $25 \%$ of MM patients without prognostic value [60]. These data could explain the significant downregulation of WRN expression in $\mathrm{MM}$ compared to normal BMPC.
Recently, a set of molecule inhibitors of WRN and BLM was characterized [61, 62]. These new molecules could open up new therapeutic strategies for targeting hematological malignancies characterized by RECQ helicase deregulation and a poor prognosis.

\section{Conclusion}

The analysis reported here demonstrates that RECQ helicase expression is deregulated in hematological malignancies compared to their normal counterparts in association with a prognostic value in AML, CLL, lymphoma and MM. Deregulation of RECQ helicases appears to play a role in tumorigenesis and could be involved in genomic instability and chemoresistance in hematological malignancies. RECQ helicases represent potent therapeutic targets for synthetic lethal approaches.

\section{Methods}

Databases: We used Oncomine Cancer Microarray database (http://www.oncomine.org) [22] and Genomicscape (http://genomicscape.com/) [63] to study gene expression of RECQ family members in nine different human hematological malignancies and their normal tissue counterpart as indicated in Table 1. To compare the gene expression of a tumor type to its normal counterpart, we used gene expression data from a same study with the same methodology. All data were log transformed, median centered per array, 


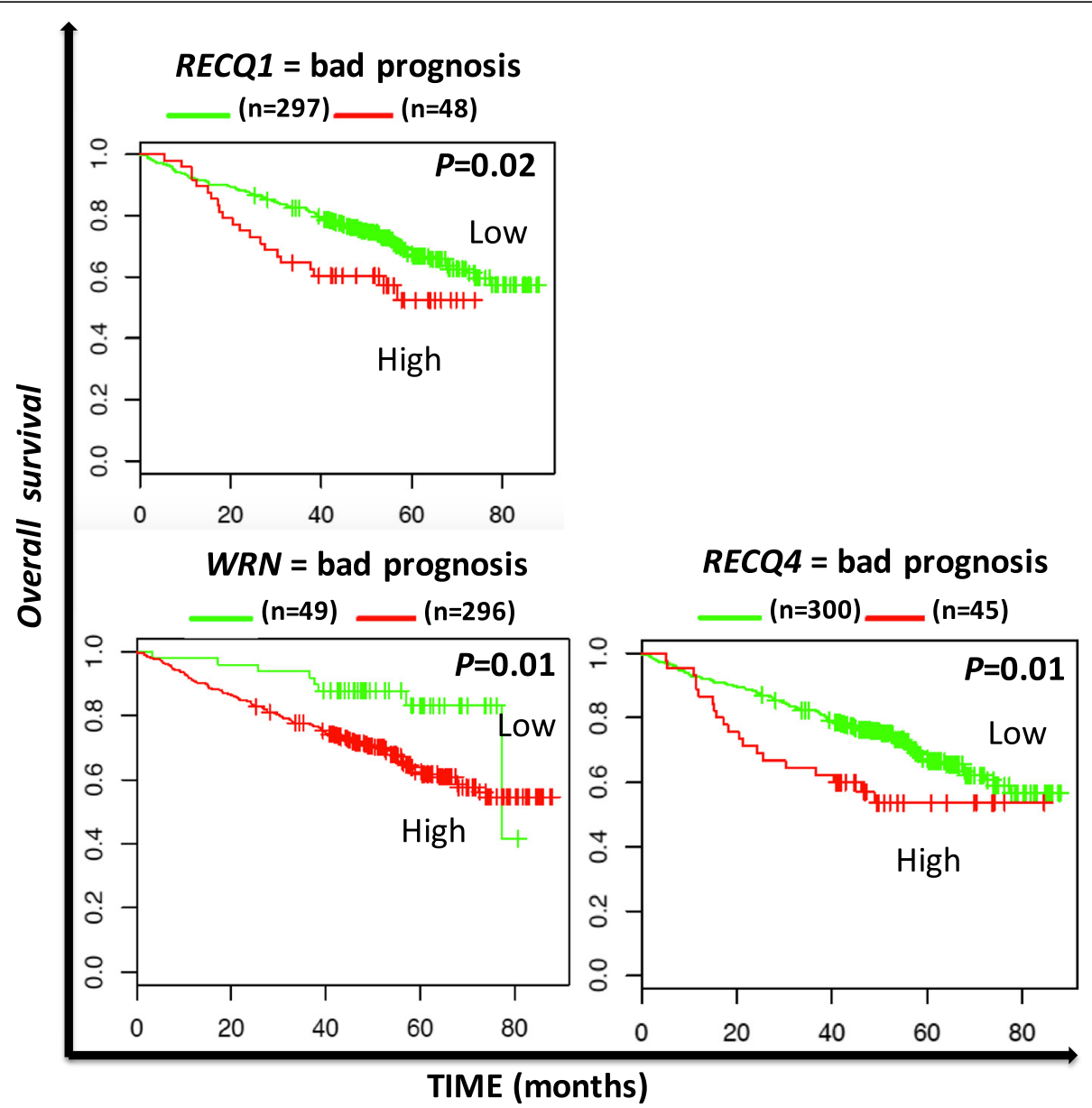

Fig. 4 Overall survival related to RECQ helicase gene expression in multiple myeloma

and the standard deviation was normalized to one per array [22].

Statistical comparisons were done with Mann-Whitney or Student $t$-test as previously published [64].

Prognosis values of each member of RECQ family in hematological malignancies were determined by using Maxstat $\mathrm{R}$ package based on publicly available data (Gene Expression Omnibus (http://www.ncbi.nlm.nih.gov/geo/); accession numbers GSE6891, GSE12417, GSE22762, GSE16131, GSE10846 and GSE4581) analyzed with Genomicscape [63] as previously reported [65].

\section{Additional file}

Additional file 1: Figure S1. RECQ helicase gene and protein expression in myeloid and lymphoid cell lines using using the human protein atlas database. RECQ1, RECQ4 and RECQ5 expression could be confirmed at protein level in myeloid and lymphoid cancer cell lines. (PDF 599 kb)

Competing interests

The authors declare that they have no competing interests.
Authors' contributions

EV performed research, bioinformatics, and participated in the writing of the paper. AK participated in the bioinformatics. PP participated in the writing of the paper. BK participated in the research and in the writing of the paper. JM supervised the research, bioinformatics, and the writing of the paper. All authors read and approved the final manuscript.

\section{Acknowledgements}

This work was supported by grants from French INCA (Institut National du Cancer) Institute (2012-109/087437), Languedoc Roussillon CRLR (R14026FF) Fondation de France (201400047510), ITMO Cancer (MM\&TT) and AXLR SATT (30041633). EV is supported by a grant from Guillaume Espoir association (Saint- Genis-Laval, France).

\section{Author details}

${ }^{1}$ Laboratory for Monitoring Innovative Therapies, Department of Biological Hematology, Hôpital Saint-Eloi - CHRU de Montpellier, 80, av. Augustin Fliche, 34295 Montpellier, Cedex 5, France. ${ }^{2}$ Institute of Human Genetics, CNRS-UPR1 142, Montpellier F-34396, France. ${ }^{3}$ University of Montpellier 1, UFR de Médecine, Montpellier, France.

Received: 5 November 2015 Accepted: 8 February 2016

Published online: 13 February 2016

\section{References}

1. Chu WK, Hickson ID. RecQ helicases: multifunctional genome caretakers. Nat Rev Cancer. 2009;9(9):644-54. doi:10.1038/nrc2682.

2. Larsen NB, Hickson ID. RecQ Helicases: Conserved Guardians of Genomic Integrity. Adv Exp Med Biol. 2013;767:161-84. doi:10.1007/978-1-4614-5037-5_8. 
3. Weinert BT, Rio DC. DNA strand displacement, strand annealing and strand swapping by the Drosophila Bloom's syndrome helicase. Nucleic Acids Res. 2007;35(4):1367-76. doi:10.1093/nar/gkl831.

4. $\quad$ Sung $\mathrm{P}$, Klein $\mathrm{H}$. Mechanism of homologous recombination: mediators and helicases take on regulatory functions. Nat Rev Mol Cell Biol. 2006;7(10): 739-50. 10. 1038/nrm2008.

5. Drosopoulos WC, Kosiyatrakul ST, Schildkraut CL. BLM helicase facilitates telomere replication during leading strand synthesis of telomeres. J Cell Biol. 2015;210(2):191-208. doi:10.1083/jcb.201410061

6. Kamath-Loeb A, Loeb LA, Fry M. The Werner syndrome protein is distinguished from the Bloom syndrome protein by its capacity to tightly bind diverse DNA structures. PLoS One. 2012;7(1):e30189. doi:10.1371/ journal.pone.0030189.

7. Damerla RR, Knickelbein KE, Strutt S, Liu FJ, Wang H, Opresko PL. Werner syndrome protein suppresses the formation of large deletions during the replication of human telomeric sequences. Cell Cycle. 2012;11(16):3036-44 doi:10.4161/cc.21399.

8. Opresko PL, Mason PA, Podell ER, Lei M, Hickson ID, Cech TR, et al. POT1 stimulates RecQ helicases WRN and BLM to unwind telomeric DNA substrates. J Biol Chem. 2005;280(37):32069-80. doi:10.1074/jbc.M505211200.

9. Chen L, Huang S, Lee L, Davalos A, Schiestl RH, Campisi J, et al. WRN, the protein deficient in Werner syndrome, plays a critical structural role in optimizing DNA repair. Aging Cell. 2003;2(4):191-9.

10. Kobayashi J, Okui M, Asaithamby A, Burma S, Chen BP, Tanimoto K, et al. WRN participates in translesion synthesis pathway through interaction with NBS1. Mech Ageing Dev. 2010;131(6):436-44. doi:10.1016/j.mad.2010.06.005.

11. Karmakar P, Snowden CM, Ramsden DA, Bohr VA. Ku heterodimer binds to both ends of the Werner protein and functional interaction occurs at the Werner N-terminus. Nucleic Acids Res. 2002;30(16):3583-91.

12. Berti M, Ray Chaudhuri A, Thangavel S, Gomathinayagam S, Kenig S, Vujanovic M, et al. Human RECQ1 promotes restart of replication forks reversed by DNA topoisomerase I inhibition. Nat Struct Mol Biol. 2013;20(3): 347-54. doi:10.1038/nsmb.2501

13. Lu X, Parvathaneni S, Hara T, Lal A, Sharma S. Replication stress induces specific enrichment of RECQ1 at common fragile sites FRA3B and FRA16D. Mol Cancer. 2013:12(1):29. doi:10.1186/1476-4598-12-29.

14. Popuri V, Croteau DL, Brosh Jr RM, Bohr VA. RECQ1 is required for cellular resistance to replication stress and catalyzes strand exchange on stalled replication fork structures. Cell Cycle. 2012;11(22):4252-65. doi:10.4161/ cc.22581.

15. Li XL, Lu X, Parvathaneni S, Bilke S, Zhang H, Thangavel S, et al. Identification of RECQ1-regulated transcriptome uncovers a role of RECQ1 in regulation of cancer cell migration and invasion. Cell Cycle. 2014;13(15):2431-45.

16. Sekelsky JJ, Brodsky MH, Rubin GM, Hawley RS. Drosophila and human RecQ5 exist in different isoforms generated by alternative splicing. Nucleic Acids Res. 1999;27(18):3762-9.

17. Hu Y, Lu X, Barnes E, Yan M, Lou H, Luo G. Recal5 and BIm RecQ DNA helicases have nonredundant roles in suppressing crossovers. Mol Cell Biol. 2005:25(9):3431-42. doi:10.1128/MCB.25.9.3431-3442.2005.

18. Hansen GM, Skapura D, Justice MJ. Genetic profile of insertion mutations in mouse leukemias and lymphomas. Genome Res. 2000;10(2):237-43.

19. Saponaro M, Kantidakis T, Mitter R, Kelly GP, Heron M, Williams H, et al. RECQL5 controls transcript elongation and suppresses genome instability associated with transcription stress. Cell. 2014;157(5):1037-49. doi:10.1016/j. cell.2014.03.048

20. Rezazadeh S. RecQ helicases; at the crossroad of genome replication, repair, and recombination. Mol Biol Rep. 2011. doi:10.1007/s11033-011-1243-y

21. Economopoulou P, Pappa V, Papageorgiou S, Dervenoulas J, Economopoulos T. Abnormalities of DNA repair mechanisms in common hematological malignancies. Leuk Lymphoma. 2011;52(4):567-82. doi:10. 3109/10428194.2010.551155.

22. Rhodes DR, Yu J, Shanker K, Deshpande N, Varambally R, Ghosh D, et al. ONCOMINE: a cancer microarray database and integrated data-mining platform. Neoplasia. 2004;6(1):1-6.

23. Basso K, Margolin AA, Stolovitzky G, Klein U, Dalla-Favera R, Califano A. Reverse engineering of regulatory networks in human B cells. Nat Genet 2005;37(4):382-90. doi:10.1038/ng1532.

24. Piccaluga PP, Agostinelli C, Califano A, Rossi M, Basso K, Zupo S, et al. Gene expression analysis of peripheral T cell lymphoma, unspecified, reveals distinct profiles and new potential therapeutic targets. J Clin Invest. 2007: 117(3):823-34. doi:10.1172/JCI26833.
25. Brune V, Tiacci E, Pfeil I, Doring C, Eckerle S, van Noesel CJ, et al. Origin and pathogenesis of nodular lymphocyte-predominant Hodgkin lymphoma as revealed by global gene expression analysis. J Exp Med. 2008:205(10):2251-68. doi:10.1084/jem.20080809.

26. Stegmaier K, Ross KN, Colavito SA, O'Malley S, Stockwell BR, Golub TR. Gene expression-based high-throughput screening(GE-HTS) and application to leukemia differentiation. Nat Genet. 2004;36(3):257-63. doi:10.1038/ng1305.

27. Zhan F, Huang Y, Colla S, Stewart JP, Hanamura I, Gupta S, et al. The molecular classification of multiple myeloma. Blood. 2006;108(6):2020-8.

28. Uhlen M, Fagerberg L, Hallstrom BM, Lindskog C, Oksvold P, Mardinoglu A, et al. Proteomics. Tissue-based map of the human proteome. Science. 2015; 347(6220):1260419. doi:10.1126/science.1260419.

29. Ponten F, Jirstrom K, Uhlen M. The Human Protein Atlas-a tool for pathology. J Pathol. 2008;216(4):387-93. doi:10.1002/path.2440.

30. Uhlen M, Bjorling E, Agaton C, Szigyarto CA, Amini B, Andersen E, et al. A human protein atlas for normal and cancer tissues based on antibody proteomics. Mol Cell Proteomics. 2005:4(12):1920-32. doi:10.1074/mcp.M500279-MCP200.

31. Verhaak RG, Wouters BJ, Erpelinck CA, Abbas $S$, Beverloo HB, Lugthart $S$, et al. Prediction of molecular subtypes in acute myeloid leukemia based on gene expression profiling. Haematologica. 2009;94(1):131-4. doi:10.3324/ haematol.13299.

32. Metzeler KH, Maharry K, Radmacher MD, Mrozek K, Margeson D, Becker H, et al. TET2 mutations improve the new European LeukemiaNet risk classification of acute myeloid leukemia: a Cancer and Leukemia Group B study. J Clin Oncol. 2011;29(10):1373-81. doi:10.1200/JCO.2010.32.7742.

33. Chen E, Ahn JS, Sykes DB, Breyfogle L, Godfrey AL, Nangalia J, et al. RECQL5 Suppresses Oncogenic JAK2-Induced Replication Stress and Genomic Instability. Cell reports. 2015;13(11):2345-52. doi:10.1016/j.celrep.2015.11.037.

34. Sun J, Wang Y, Xia Y, Xu Y, Ouyang T, Li J, et al. Mutations in RECQL Gene Are Associated with Predisposition to Breast Cancer. PLoS Genet. 2015;11(5): e1005228. doi:10.1371/journal.pgen.1005228.

35. Cybulski C, Carrot-Zhang J, Kluzniak W, Rivera B, Kashyap A, Wokolorczyk D, et al. Germline RECQL mutations are associated with breast cancer susceptibility. Nat Genet. 2015:47(6):643-6. doi:10.1038/ng.3284.

36. Leich E, Salaverria I, Bea S, Zettl A, Wright G, Moreno V, et al. Follicular lymphomas with and without translocation $\mathrm{t}(14 ; 18)$ differ in gene expression profiles and genetic alterations. Blood. 2009;114(4):826-34. doi: 10.1182/blood-2009-01-198580.

37. Lenz G, Wright G, Dave SS, Xiao W, Powell J, Zhao H, et al. Stromal gene signatures in large-B-cell lymphomas. N Engl J Med. 2008;359(22):2313-23. doi:10.1056/NEJMoa0802885.

38. Suhasini AN, Brosh Jr RM. Fanconi anemia and Bloom's syndrome crosstalk through FANCJ-BLM helicase interaction. Trends Genet. 2012;28(1):7-13. doi: 10.1016/j.tig.2011.09.003

39. Poppe B, Van Limbergen H, Van Roy N, Vandecruys E, De Paepe A, Benoit $Y$, et al. Chromosomal aberrations in Bloom syndrome patients with myeloid malignancies. Cancer Genet Cytogenet. 2001;128(1):39-42.

40. German J, Sanz MM, Ciocci S, Ye TZ, Ellis NA. Syndrome-causing mutations of the BLM gene in persons in the Bloom's Syndrome Registry. Hum Mutat. 2007;28(8):743-53. doi:10.1002/humu.20501

41. Goto M, Miller RW, Ishikawa Y, Sugano H. Excess of rare cancers in Werner syndrome (adult progeria). Cancer Epidemiol Biomarkers Prev. 1996;5(4):239-46.

42. Esposito MT, So CW. DNA damage accumulation and repair defects in acute myeloid leukemia: implications for pathogenesis, disease progression, and chemotherapy resistance. Chromosoma. 2014;123(6):545-61. doi:10.1007/ s00412-014-0482-9.

43. Zhong S, Hu P, Ye TZ, Stan R, Ellis NA, Pandolfi PP. A role for PML and the nuclear body in genomic stability. Oncogene. 1999;18(56):7941-7. doi:10.1038/sj.onc.1203367.

44. Sanada S, Futami K, Terada A, Yonemoto K, Ogasawara S, Akiba J, et al. RECQL1 DNA repair helicase: a potential therapeutic target and a proliferative marker against ovarian cancer. PLoS One. 2013;8(8):e72820. doi: 10.1371/journal.pone.0072820.

45. Matsushita Y, Yokoyama Y, Yoshida H, Osawa Y, Mizunuma M, Shigeto T, et al. The level of RECQL1 expression is a prognostic factor for epithelial ovarian cancer. J Ovarian Res. 2014;7:107. doi:10.1186/s13048-014-0107-1

46. Gennery AR, Cant AJ, Jeggo PA. Immunodeficiency associated with DNA repair defects. Clin Exp Immunol. 2000:121(1):1-7.

47. Caddle LB, Hasham MG, Schott WH, Shirley BJ, Mills KD. Homologous recombination is necessary for normal lymphocyte development. Mol Cell Biol. 2008;28(7):2295-303. doi:10.1128/MCB.02139-07. 
48. Hasham MG, Donghia NM, Coffey E, Maynard J, Snow KJ, Ames J, et al. Widespread genomic breaks generated by activation-induced cytidine deaminase are prevented by homologous recombination. Nat Immunol. 2010;11(9):820-6. doi:10.1038/ni.1909.

49. Sidorova JM, Li N, Folch A, Monnat Jr RJ. The RecQ helicase WRN is required for normal replication fork progression after DNA damage or replication fork arrest. Cell Cycle. 2008;7(6):796-807.

50. Yin L. Chondroitin synthase 1 is a key molecule in myeloma cell-osteoclast interactions. J Biol Chem. 2005;280(16):15666-72.

51. Gu X, Booth CJ, Liu Z, Strout MP. AID-associated DNA repair pathways regulate malignant transformation in a murine model of BCL6-driven diffuse large B cell lymphoma. Blood. 2015. doi:10.1182/blood-2015-02-628164

52. Hathcock KS, Padilla-Nash HM, Camps J, Shin DM, Triner D, Shaffer AL, 3rd et al. ATM deficiency in absence of T cells promotes development of NF-kB-dependent murine B cell lymphomas that resemble human ABC DLBCL. Blood. 2015. doi:10.1182/blood-2015-06-654749

53. Bret C, Klein B, Cartron G, Schved JF, Constantinou A, Pasero P et al. DNA repair in diffuse large B-cell lymphoma: a molecular portrait. Br J Haematol. 2014. doi:10.1111/bjh.13206

54. Bret C, Klein B, Moreaux J. Gene expression-based risk score in diffuse large B-cell lymphoma. Oncotarget. 2012;3(12):1700-10.

55. Kwok M, Davies N, Agathanggelou A, Smith E, Petermann E, Yates E, et al. Synthetic lethality in chronic lymphocytic leukaemia with DNA damage response defects by targeting the ATR pathway. Lancet. 2015;385 Suppl 1: S58. doi:10.1016/S0140-6736(15)60373-7.

56. Bret C, Klein B, Moreaux J. Nucleotide excision DNA repair pathway as a therapeutic target in patients with high-risk diffuse large B cell lymphoma. Cell Cycle. 2013;12(12):1811-2. doi:10.4161/cc.25115.

57. Cottini F, Hideshima T, Suzuki R, Tai YT, Bianchini G, Richardson PG, et al. Synthetic Lethal Approaches Exploiting DNA Damage in Aggressive Myeloma. Cancer Discov. 2015;5(9):972-87. doi:10.1158/2159-8290.CD-14-0943.

58. Hose D, Reme T, Hielscher T, Moreaux J, Messner T, Seckinger A, et al. Proliferation is a central independent prognostic factor and target for personalized and risk-adapted treatment in multiple myeloma. Haematologica. 2011;96(1):87-95. doi:10.3324/haematol.2010.030296.

59. Kassambara A, Gourzones-Dmitriev C, Sahota S, Reme T, Moreaux J, Goldschmidt $\mathrm{H}$, et al. A DNA repair pathway score predicts survival in human multiple myeloma: the potential for therapeutic strategy. Oncotarget. 2014;5(9):2487-98.

60. Walker BA, Leone PE, Chiecchio L, Dickens NJ, Jenner MW, Boyd KD, et al. A compendium of myeloma-associated chromosomal copy number abnormalities and their prognostic value. Blood. 2010;116(15):e56-65. doi:10. 1182/blood-2010-04-279596.

61. Aggarwal M, Banerjee T, Sommers JA, Brosh Jr RM. Targeting an Achilles' heel of cancer with a WRN helicase inhibitor. Cell Cycle. 2013;12(20):3329-35. doi:10.4161/cc.26320.

62. Nguyen GH, Dexheimer TS, Rosenthal AS, Chu WK, Singh DK, Mosedale G, et al. A small molecule inhibitor of the BLM helicase modulates chromosome stability in human cells. Chem Biol. 2013;20(1):55-62. doi:10. 1016/..chembiol.2012.10.016.

63. Kassambara A, Reme T, Jourdan M, Fest T, Hose D, Tarte K, et al. GenomicScape: an easy-to-use web tool for gene expression data analysis. Application to investigate the molecular events in the differentiation of $B$ cells into plasma cells. PLoS Comput Biol. 2015;11(1):e1004077. doi:10.1371/ journal.pcbi.1004077.

64. Kassambara A, Klein B, Moreaux J. MMSET is overexpressed in cancers: link with tumor aggressiveness. Biochem Biophys Res Commun. 2009;379(4): 840-5. doi:10.1016/j.bbrc.2008.12.093.

65. Kassambara A, Hose D, Moreaux J, Walker BA, Protopopov A, Reme T, et al. Genes with a spike expression are clustered in chromosome (sub)bands and spike (sub)bands have a powerful prognostic value in patients with multiple myeloma. Haematologica. 2012;97(4):622-30. doi:10.3324/haematol.2011.046821.

66. Moreaux J, Kassambara A, Hose D, Klein B. STEAP1 is overexpressed in cancers: A promising therapeutic target. Biochem Biophys Res Commun. 2012:429(3-4):148-55. doi:10.1016/j.bbrc.2012.10.123.

\section{Submit your next manuscript to BioMed Central and we will help you at every step:}

- We accept pre-submission inquiries

- Our selector tool helps you to find the most relevant journal

- We provide round the clock customer support

- Convenient online submission

- Thorough peer review

- Inclusion in PubMed and all major indexing services

- Maximum visibility for your research

Submit your manuscript at www.biomedcentral.com/submit
() BioMed Central 